\title{
The Effect of Combined Therapy with Tamsulosin Hydrochloride and Meloxicam in Patients with Benign Prostatic Hyperplasia Symptoms and Impact on Nocturia and Sleep Quality
}

\author{
Sacit Nuri Gorgel, Ertugrul Sefik, Osman Kose, Vural Olgunelma, Evren Sahin \\ Izmir Katip Celebi University, Ataturk Training and Research Hospital, Izmir, Turkey
}

\section{ABSTRACT}

Purpose: We aimed to compare the effect and feasibility of a combined therapy with tamsulosin hydrochloride plus meloxicam, and tamsulosin hydrochloride alone in patients with benign prostate hyperplasia symptoms and impact on nocturia and sleep quality. Materials and Methods: Four hundred male patients were included in this study between 2008 and 2011. Patients were randomly divided into two groups: one received tamsulosin hydrochloride $0.4 \mathrm{mg}$ (Group 1, 200 patients) and the other tamsulosin hydrochloride 0.4 mg plus meloxicam $15 \mathrm{mg}$ (Group 2, 200 patients) prospectively. Patients were evaluated for benign prostate hyperplasia (BPH) symptoms according to the American Urological Association clinical guidelines and sleep quality according to Pittsburgh Sleep Quality Index (PSQI). Patients were reevaluated after three months of treatment. The International Prostatic Symptom Score (IPSS), IPSS-Quality of Life (IPSS-QoL), maximal urinary flow rates (Qmax), average urinary flow rates (AFR), post void residual urine volumes (PVR), nocturia and Pittsburgh Sleep Quality Score (PSQS) were recorded at baseline and after three months.

Results: Mean age was $63.3 \pm 6.6$ and $61.4 \pm 7.5$ years in groups 1 and 2 , respectively $(\mathrm{p}=0.245)$. There were no statistically significant differences between both groups. Also, baseline prostate specific antigen (PSA), prostate volume, creatinine, International Prostatic Symptom Score (IPSS), IPSS-Quality of Life (IPSS-QoL), maximal urinary flow rates (Qmax), average urinary flow rates (AFR), post void residual urine volumes (PVR), nocturia and Pittsburgh Sleep Quality Score (PSQS) were similar in both groups.

In addition, the total IPSS, IPSS-QoL, PVR, nocturia, and PSQS were significantly lower in Group 2 compared with Group 1 after treatment $(\mathrm{p}<0.05)$. Qmax and AFR were higher significantly in Group 2 compared with Group 1 after treatment $(\mathrm{p}<0.05)$.

Conclusions: Cyclooxygenase (COX)-2 inhibitors in combination with an alpha blocker may decrease benign prostatic hyperplasia symptoms and increase sleep quality without serious side effects.

\section{ARTICLE INFO}

\section{Key words:}

benign prostatic hyperplasia; tamsulosin; cyclooxigenase

inhibitor; sleep quality

Int Braz J Urol. 2013; 39: 657-62

Submitted for publication:

January 23, 2013

Accepted after revision:

September 18, 2013

\section{INTRODUCTION}

Benign prostatic hyperplasia $(\mathrm{BPH})$ is one of the most common diseases affecting aging men.
In a study of men residing in Olmsted County, Minnesota, 26 percent of those aged 40-49 years experienced moderate to severe lower urinary tract symptoms, and this proportion increased to 45 
percent among those aged 70-79 years (1). Lower urinary tract symptoms (LUTS) in elderly men were traditionally attributed to the enlarging prostate. The mechanisms invoked were one or all of the following: histological benign prostatic hyperplasia, benign prostatic enlargement, or benign prostatic obstruction (2).

Historically, it was assumed that alpha-1-blockers act by inhibiting the effect of endogenously released noradrenaline on prostate smooth muscle cells, thereby reducing prostate tone and bladder outlet obstruction. Contraction of the human prostate is mediated predominantly, if not exclusively, by alpha-1A-adrenoceptors (3). Alpha blocker agents have been used for more than a decade in the treatment of LUTS. Previously published meta-analysis has shown that 30\%-40\% of patients with LUTS showed improvements in the symptoms, and there was a 20\%-30\% increase observed in the maximum flow after alpha blocker therapy (4).

More recently, some clinical trials were conducted for obtaining better results with medical therapy that compared the combination therapies and monotherapy for the treatment of BPH; encouraging results were observed that favored combination therapies. In one of these clinical trials, combination therapy with finasteride and rofeco$\mathrm{xib}$, which is a selective cyclooxygenase (COX)-2 inhibitor, yielded better results when compared with finasteride monotherapy (5).

The association between $\mathrm{BPH}$ and inflammation has been known for several years. COX is a key enzyme in inflammation-converting arachidonic acid to prostaglandin and other eicosanoids. Two isoforms of COX exist, namely, cyclooxygenase-1 (COX-1) and COX-2. The highest level of COX in the human body has been shown to be found in the prostate, and the highest amount of COX-2 expression in the prostate occurs in the prostatic smooth muscle cells (6). So we used COX2 inhibitors in a combined therapy with an alpha blocker for BPH symptoms.

$\mathrm{BPH}$ is known to be primarily a disease of prostatic smooth muscle cells, and prostaglandins have an essential role in the function and growing of smooth muscle cells. The knowledge of high levels of COX-2 expression in the prostatic smooth muscle cells in prostate cancer and BPH forms the basis for the potential use of selective COX-2 inhibitors in the treatment of BPH (7).

Moreover, several clinical trials showed increased COX-2 expression and prostaglandin production in partial bladder outlet obstruction, which may cause detrusor overactivity due to bladder dysfunction (8-10).

In this study, we aimed to compare the effects of tamsulosin hydrochloride and meloxicam combination therapy with tamsulosin hydrochloride monotherapy for benign prostate hyperplasia symptoms and impact on sleep quality and nocturia.

\section{MATERIALS AND METHODS}

Four hundred patients were included in this study between 2008 and 2011. Patients were randomly divided into two groups: one received tamsulosin hydrochloride $0.4 \mathrm{mg}$ (Group 1, 200 patients) and the other tamsulosin hydrochloride 0.4 mg plus meloxicam $15 \mathrm{mg}$ (Group 2, 200 patients) prospectively. Patients were evaluated for benign prostate hyperplasia (BPH) symptoms according to the American Urological Association clinical guidelines and sleep quality according to Pittsburgh Sleep Quality Index (PSQI).

The International Prostatic Symptom Score (IPSS), IPSS-Quality of Life (IPSS-QoL), maximal urinary flow rates (Qmax), average urinary flow rates (AFR), post void residual urine volumes (PVR), nocturia and Pittsburgh Sleep Quality Score (PSQS) were recorded at baseline and again after three months.

This study included men aged 50-75 years, with symptoms of BPH (IPSS range 8-19), a maximum urinary flow rate ( $\max$ ) of $\geq 5$ and $\leq 15$ $\mathrm{mL} / \mathrm{s}$, total voided volume of $\geq 150 \mathrm{~mL}, 2$ or more episodes of nocturia, and Pittsburgh Sleep Quality Score $(\mathrm{PSQS})>5$.

Patients with previous prostate surgery, suspected digital rectal examination (DRE) or PSA value of $>4 \mathrm{ng} / \mathrm{mL}$ were excluded from the study. Other exclusion criteria were urethral stricture, bladder diverticulum, bladder stone, recurrent urinary tract infections, recurrent catheterization, active urinary tract infection, neurogenic bladder, residual urinary volumes $>200 \mathrm{~mL}$, history of previous 
or continuing medication with 5-alpha reductase inhibitors, alpha blockers, antiandrogens and phytotherapeutic agents. 46 patients were excluded because of lost of follow-up.

This study was a prospective and randomized trial. Descriptive statistics were used to characterize variables in the population and in each group of treatment (mean \pm SD). Mean changes adjusted for baseline are presented and tested using the Wilcoxon signed-rank test. Pair-wise treatment comparisons were made. All statistical tests were two-tailed with a 0.05 level of significance for treatment effects. Ethical committee approval was taken for combined therapy.

\section{RESULTS}

Four hundred consecutive patients who entered the study were randomized to treatment. There were 200 patients in group 1 and 200 patients in group 2. All 400 subjects completed the three month period of the study.

Mean age was $63.3 \pm 6.6$ and $61.4 \pm 7.5$ years in groups 1 and 2 , respectively $(\mathrm{p}=0.245)$. There were no statistically significant differences between boths groups. Also, baseline prostate spesific antigen (PSA), prostate volume, creatinine, International Prostatic Symptom Score (IPSS), IPSS-Quality of Life (IPSS-QoL), maximal urinary flow rates (Qmax), average urinary flow rates (AFR), post void residual urine volumes (PVR), nocturia and Pittsburgh Sleep Quality Score (PSQS) were similar for the both groups (Table-1).

Mean decrease in total IPSS score after the treatment was $6.1 \pm 4.6$ and $9.8 \pm 5.5$ points in groups 1 and 2, respectively $(\mathrm{p}<0.05)$. The average decrease in IPSS-QoL scores was $1.3 \pm 1.1$ points in group 1 and $2.5 \pm 1.2$ points in group 2 after the treatment $(\mathrm{p}<0.05)$. Maximum flow rates $(\mathrm{Qmax})$ were statistically higher in group 2 after the treatment $(4.1 \pm 2.5$ vs $6.3 \pm 2.8 \mathrm{~mL} / \mathrm{s})(\mathrm{p}<0.05)$. The mean increase of average urinary flow rates (AFR) was 2.2 $\pm 1.8 \mathrm{~mL}$ in group 1 and $3.9 \pm 3.2 \mathrm{~mL}$ in group 2 after the treatment $(\mathrm{P}<0.03)$. The mean decrease of PVR urine volumes was $16.5 \pm 25.8 \mathrm{~mL}$ in group 1 and $32.9 \pm 38.2 \mathrm{~mL}$ in group 2 after the treatment $(\mathrm{P}<0.01)$. The mean decrease of PSQS was $4.1 \pm$ $2.8 \mathrm{~mL}$ in group 1 and $7.9 \pm 3.2 \mathrm{~mL}$ in group 2

Table 1 - Baseline characteristics of the patients for both groups.

\begin{tabular}{lccc}
\hline & Group 1 (mean $\pm \mathrm{SD})$ & Group 2 (mean $\pm \mathrm{SD})$ & $\mathrm{p}$ \\
\hline Age (years) & $63.3 \pm 6.6$ & $61.4 \pm 7.5$ & 0.245 \\
PSA (ng/mL) & $2.1 \pm 1.8$ & $2.2 \pm 1.9$ & 0.447 \\
Prostate volume (mL) & $43.3 \pm 13.6$ & $39.3 \pm 12.4$ & 0.345 \\
Creatinine (mg/dL) & $1.2 \pm 0.3$ & $1.2 \pm 0.4$ & 0.117 \\
Total IPSS & $15.3 \pm 3.6$ & $14.9 \pm 4.2$ & 0.284 \\
IPSS-Q0L & $3.9 \pm 1.2$ & $3.8 \pm 1.1$ & 0.362 \\
Qmax (mL/s) & $10.6 \pm 2.3$ & $11.1 \pm 2.4$ & 0.688 \\
AFR (mL/s) & $6.1 \pm 1.2$ & $5.9 \pm 1.3$ & 0.542 \\
PVR (mL) & $72.1 \pm 43.3$ & $69.9 \pm 38.3$ & 0.104 \\
Episodes of nocturia & $3.1 \pm 0.7$ & $2.8 \pm 0.6$ & 0.124 \\
PSQS & $10.3 \pm 3.4$ & $10.7 \pm 4.3$ & 0.415 \\
\hline
\end{tabular}

IPSS = International Prostatic Symptom Score; QoL = Quality of Life, $\mathbf{Q m a x}=$ Maximal urinary flow rates, $\mathbf{A F R}=$ Average urinary flow rates, $\mathbf{P S Q S}=$ Pittsburgh Sleep Quality Score 
after the treatment $(p<0.02)$. The mean decrease of nocturia episodes was $1.4 \pm 1.1 \mathrm{~mL}$ in group 1 and $2.7 \pm 1.2 \mathrm{~mL}$ in group 2 after the treatment $(\mathrm{p}$ $<0.04)$ (Table-2).

Treatments were generally well tolerated. No serious adverse events causing the discontinuation of the treatment were observed during the treatment course in both groups.

\section{DISCUSSION}

Lower urinary tract symptom severity is a risk factor for severe sleep disturbance in men. While nocturia was significantly associated with period for development from small lesions to become clinically manifested (14). In these both prostatic diseases, there is an imbalance between prostate cell growth and apoptosis. This imbalance is complex and influenced by microenvironment around prostate such as growth factors, cytokines and steroid hormones. These factors stimulate proliferation and minimize cell apoptosis (15). The role of inflammation in prostate diseases is suggested by the presence of inflammatory cells within the prostate in both prostatic diseases (16).

Di Silverio et al. demonstrated a correlation of higher inflammatory infiltrates present in bigger prostate volume and more prone to progression of

Table 2 - Mean changes over baseline of both groups after the treatment.

\begin{tabular}{lccc}
\hline & Group 1 (mean \pm SD) & Group 2 (mean \pm SD) & $p$ \\
\hline PSQS & $-4.1 \pm 2.8$ & $-7.9 \pm 3.2$ & $<0.02$ \\
Episodes of nocturia & $-1.4 \pm 1.1$ & $-2.7 \pm 1.2$ & $<0.04$ \\
Total IPSS & $-6.1 \pm 4.6$ & $-9.8 \pm 5.5$ & $<0.05$ \\
IPSS-Q0L & $-1.3 \pm 1.1$ & $-2.5 \pm 1.2$ & $<0.05$ \\
Qmax (mL/s) & $4.1 \pm 2.5$ & $6.3 \pm 2.8$ & $<0.05$ \\
AFR (mL/s) & $2.2 \pm 1.8$ & $3.9 \pm 3.2$ & $<0.03$ \\
\hline PVR (mL) & $-16.5 \pm 25.8$ & $-32.9 \pm 38.2$ & $<0.01$ \\
\hline
\end{tabular}

IPSS = International Prostatic Symptom Score; $\mathbf{Q} \mathbf{0 L}=$ Quality of Life; $\mathbf{Q m a x}=$ Maximal urinary flow rates; $\mathbf{A F R}=$ Average urinary flow rates; $\mathbf{P S Q S}=$ Pittsburgh Sleep Quality Score; PVR = Post void residual urine volumes

sleep disturbance, other lower urinary tract symptoms were also independent predictors of sleep dysfunction (11). Nocturia in patients with benign prostatic hyperplasia (BPH) is one of the most uncomfortable symptoms of the disease. It greatly affects quality of life by deteriorating the quality of sleep and disturbing activities during the day (12). The Pittsburg Sleep Quality Index (PSQI) is an effective instrument used to measure the quality and patterns of sleep in adults (13). In our study, patients were evaluated for sleep quality according to Pittsburgh Sleep Quality Index (PSQI).

Benign prostatic hyperplasia and prostate cancer are chronic diseases that need a long symptoms, risk of acute urinary retention and risk for surgery (17).

Some clinical trials show better results with combination therapies in benign prostatic hyperplasia symptoms. One of them is the MTOPS (Medical Therapy of Prostatic Symptoms) study that compared the long-term effects of combined therapy with doxazosin plus finasteride with either drug alone. The results of MTOPS showed that combination therapy was superior to monotherapy, which significantly reduced the risk of progression and the need for surgery in the long term (18).

It is well known that inflammation and BPH coexist in the prostatectomy specimens (19). 
COX is a key enzyme in inflammation and found in 2 isoforms, COX-1 and COX-2, the latter especially activated during inflammation in the bladder (20). Chronic inflammation continuously produces cyclooxygenase-2 (COX-2) (21). Meloxicam is a non steroidal anti-inflammatory drug with a selective inhibition of cyclooxygenase-2 (COX2) (22). Although there is much more interest in chemoprevention of prostate cancer with COX-2, it has been shown that COX-2 expression is increased also in BPH and prostatic smooth muscle cells (23). The co-expression of COX-1 and COX-2 proteins in benign and malignant human prostates, and the induction and significantly greater expression of COX-2 in cancer were also associated with tumour grade. The regular use of nonsteroidal anti-inflammatory drugs is associated with a reduced incidence of cancers. The present results provide the basis for a potential role for COX-2 inhibitors in the prevention and treatment of prostate cancer (24). Despite such strong association between inflammation, COX-2, and $\mathrm{BPH}$, clinical trials evaluating the effects of COX2 inhibitors in LUTS and BPH are scarce (25).

Studies have shown that a reduction from baseline in IPSS of $\geq 30 \%$ and a Qmax improvement $>3 \mathrm{~mL} / \mathrm{s}$ after treatment is considered clinically significant. Kirby et al. showed in their integrated analysis of the two studies that among patients receiving doxazosin-GITS, 71.2\% had a reduction from baseline in IPSS of $\geq 30 \%$ at the final visit, as did $71.1 \%$ of patients in the doxazosin-S group and 53.3\% of patients in the placebo group. Considering better treatment outcomes in group 2 compared with $8 \mathrm{mg}$ doxazosin, our results may suggest that combined use of doxazosin with tenoxicam might be more effective (26).

In our study, combined therapy with meloxicam, a selective COX-2 inhibitor, plus tamsulosin hydrochloride resulted in better improvement of benign prostatic hyperplasia symptoms, nocturia and sleep quality compared with tamsulosin hydrochloride alone.

We acknowledge limitations of this study. Absence of meloxicam or placebo only group may have changed our results, and therefore the favorable effect of combined therapy observed in our study should be interpreted with caution.
Limitations of the study: BPH is a chronic disease and this trial involved only a three month follow-up period. There is no long term follow-up period.

\section{CONCLUSIONS}

In conclusion, we suggest that combination therapy with an alpha blocker and COX-2 inhibitor may be a safe and effective treatment option for benign prostate hyperplasia symptoms and impact on sleep quality and nocturia. In particular, patients suffering from mainly the sleep quality who do not respond to alpha blocker therapy might be offered combination therapy.

\section{CONFLICT OF INTEREST}

None declared.

\section{REFERENCES}

1. Sarma AV, Wei JT, Jacobson DJ, Dunn RL, Roberts RO, Girman CJ, et al.: Comparison of lower urinary tract symptom severity and associated bother between community-dwelling black and whitemen: the Olmsted County Study of Urinary Symptoms and Health Status and the Flint Men's Health Study. Urology. 2003; 61: 1086-91.

2. Chapple CR, Roehrborn CG: A shifted paradigm for the further understanding, evaluation, and treatment of lower urinary tract symptoms in men: focus on the bladder. Eur Urol. 2006; 49: 651-8.

3. Michel MC, Vrydag W: Alpha1-, alpha2- and beta-adrenoceptors in the urinary bladder, urethra and prostate. Br J Pharmacol. 2006; 147: S88-119.

4. Madersbacher S, Alivizatos G, Nordling J, Sanz CR, Emberton M, de la Rosette JJ: EAU 2004 guidelines on assessment, therapy and follow-up of men with lower urinary tract symptoms suggestive of benignprostatic obstruction (BPH guidelines). Eur Urol. 2004; 46: 547-54.

5. Di Silverio F, Bosman C, Salvatori M, Albanesi L, Proietti Pannunzi L, Ciccariello M, et al.: Combination therapy with rofecoxib and finasteride in the treatment of men with lower urinary tract symptoms (LUTS) and benign prostatic hyperplasia (BPH). Eur Urol. 2005; 47: 72-8; discussion 78-9.

6. Kirschenbaum A, Klausner AP, Lee R, Unger P, Yao S, Liu XH,et al.: Expression of cyclooxygenase-1 and cyclooxygenase-2 in the human prostate. Urology. 2000; 56: 671-6. 
7. Hussain T, Gupta S, Mukhtar H: Cyclooxygenase-2 and prostate carcinogenesis. Cancer Lett. 2003; 191: 125-35.

8. Masick JM, Levin RM, Hass MA: The effect of partial outlet obstruction on prostaglandin generation in the rabbit urinary bladder. Prostaglandins Other Lipid Mediat. 2001; 66: 211-9.

9. Park JM, Yang T, Arend LJ, Smart AM, Schnermann JB, Briggs JP: Cyclooxygenase-2 is expressed in bladder during fetal development and stimulated by outlet obstruction. Am J Physiol. 1997; 273: F538-44.

10. Maggi CA: Prostanoids as local modulators of reflex micturition. Pharmacol Res. 1992; 25: 13-20.

11. Helfand BT, McVary KT, Meleth S, Sharp V, Foster H, Naslund $M$, et al:: The relationship between lower urinary tract symptom severity and sleep disturbance in the CAMUS trial. J Urol. 2011; 185: 2223-8.

12. Asplund $\mathrm{R}$, Aberg $\mathrm{H}$ : Health of the elderly with regard to sleep and nocturnal micturition. Scand J Prim Health Care. 1992; 10: 98-104.

13. Buysse DJ, Reynolds CF 3rd, Monk TH, Berman SR, Kupfer DJ: The Pittsburgh Sleep Quality Index: a new instrument for psychiatric practice and research. Psychiatry Res. 1989; 28: 193-213.

14. Nuñez $C$, Cansino JR, Bethencourt $F$, Pérez-Utrilla $M$, Fraile $B$, Martínez-Onsurbe $P$, et al.: TNF/IL-1/NIK/NF-kappa B transduction pathway: a comparative study in normal and pathological human prostate (benign hyperplasia and carcinoma). Histopathology. 2008; 53: 166-76.

15. Sciarra A, Mariotti G, Salciccia S, Autran Gomez A, Monti $\mathrm{S}$, Toscano $\mathrm{V}$, et al.: Prostate growth and inflammation. J Steroid Biochem Mol Biol. 2008; 108: 254-60.

16. Novara G, Galfano A, Berto RB, Ficarra V, Navarrete RV, Artibani W: Inflammation, apoptosis, and $\mathrm{BPH}$ : What is the evidence? Eur Urol Suppl. 2006; 5: 401-9.

17. Di Silverio F, Gentile V, De Matteis A, Mariotti G, Giuseppe V, Luigi $P A$, et al.: Distribution of inflammation, pre-malignant lesions, incidental carcinoma in histologically confirmed benign prostatic hyperplasia: a retrospective analysis. Eur Urol. 2003; 43: 164-75.
18. McConnell JD, Roehrborn CG, Bautista OM, Andriole GL Jr, Dixon CM, Kusek JW, et al.: The long-term effect of doxazosin, finasteride, and combination therapy on the clinical progression of benign prostatic hyperplasia. N Engl J Med. 2003; 349: 2387-98.

19. Nickel JC, Downey J, Young I, Boag S: Asymptomatic inflammation and/or infection in benign prostatic hyperplasia. BJU Int. 1999; 84: 976-81.

20. Andersson KE: LUTS treatment: future treatment options. Neurourol Urodyn. 2007; 26: 934-47.

21. Caruso C, Balistreri CR, Candore G, Carruba G, ColonnaRomano G, Di Bona D, et al.: Polymorphisms of pro-inflammatory genes and prostate cancer risk: a pharmacogenomic approach. Cancer Immunol Immunother. 2009; 58: 1919-33

22. Mitchell JA, Akarasereenont P, Thiemermann C, Flower RJ, Vane JR: Selectivity of nonsteroidal antiinflammatory drugs as inhibitors of constitutive and inducible cyclooxygenase. Proc Natl Acad Sci U S A. 1993; 90: 11693-7.

23. Wang W, Bergh A, Damber JE: Chronic inflammation in benign prostate hyperplasia is associated with focal upregulation of cyclooxygenase-2, Bcl-2, and cell proliferation in the glandular epithelium. Prostate. 2004; 61: 60-72.

24. Madaan S, Abel PD, Chaudhary KS, Hewitt R, Stott MA, Stamp GW, et al.: Cytoplasmic induction and over-expression of cyclooxygenase-2 in human prostate cancer: implications for prevention andtreatment. BJU Int. 2000; 86: 736-41.

25. Di Silverio F, Bosman C, Salvatori M, Albanesi L, Proietti Pannunzi L, Ciccariello M, et al.: Combination therapy with rofecoxib and finasteride in the treatment of men with lower urinary tract symptoms (LUTS) and benign prostatic hyperplasia (BPH). Eur Urol. 2005; 47: 72-8; discussion 78-9

26. Kirby RS, Andersen M, Gratzke P, Dahlstrand C, Høye K: A combined analysis of double-blind trials of the efficacy and tolerability of doxazosin-gastrointestinal therapeutic system, doxazosin standard and placebo in patients with benign prostatic hyperplasia. BJU Int. 2001; 87: 192-200.

Correspondence address:

Sacit Nuri Gorgel, MD

Izmir Katip Celebi University,

Ataturk Training and Research Hospital, Izmir, Turkey

Telephone: + 90532 688-2910

E-mail: sngorgel@hotmail.com 